ture exerted by the ice-bag at the nape of the neck, in close proximity to the heat-regulating centres, is worthy of notice. Urethan given in large doses, on some occasions as much as eighty grains at a time, had little or no influence in procuring sleep, though it sometimes seemed to allay the extreme restlessness, which was such a troublesome factor throughout this case. Its principal effect, however, appeared to be exerted in improving and steadying the pulse.

Wallingford, Berks.

BRIEF NOTES OF THREE CASES OF

INTESTINAL OBSTRUCTION ILLUSTRATING SOME POSSIBLE ERRORS OF DIAGNOSIS.

BY HAROLD G. TAYLOR, M.D. LOND.,

ASSISTLYT MEDICAL OFFICER, ROYAL ALBERT ASYLUM, LANCASTIER.

CASE 1. Chronic intestinal obstruction simulating tabes mesenterica.-W.M. T-, an imbecile boy aged sixteen, with family history of phthisis. Towards the end of August, 1882, it was noticed that he had fallen off a good deal in flesh, and had occasional attacks of abdominal pain and diarrhoea. On examination of the abdomen there was found to be general enlargement with prominence of the superficial veins, and apparently a little ascites. On Sept. 21st a tumour was felt in the right iliac region, which subsequently extended into the hypogastric region; it was hard, lobulated, and easily mapped out with the hand, being evidently distinct from the liver and kidney. The symptoms were gradual emaciation, abdominal pain, occasional vomiting (which, however, was never copious or uncontrollable), and a tendency to diarrhoea, the motions being of a dark muddy colour. The morning temperature was generally about normal; in the evening it was usually a little over $100^{\circ}$, but sometimes as high as $102^{\circ}$. He died on Oct. 31st without any fresh symptoms. The diagnosis made was tubercular disease of the mesenteric glands. The postmortem examination showed that the cause of death was intestinal obstruction. The tumour felt during life consisted of coils of intestine closely matted together by peritoneal adhesions, and distended by a dense fæcal mass consisting almost entirely of potato parings.

CASE 2. Acute intestinal obstruction simulating choleraic diarrhoea.-S. B- , an imbecile boy aged sixteen, with feeble circulation and subject to occasional attacks of diarrhœe. On July 30 th, 1883, some friends came to see him and gave him a good many sweets. The same night he had diarrhoea badly; the next day he looked very pale and ill; about noon the diarrhoea recurred, he became very blue, and his pulse was almost imperceptible. He was put to bed and stimulants administered; he looked better, but diarrhoea continued.Aug. 1st: He was restless during the night, and the diarrhœa still continues; the stools are liquid, of a dark-greenish mud colour; he complains of no pain but is thirsty; the hands and feet are cold and the pulse imperceptible; temperature in the axilla $102^{\circ}$, no abdominal distension; tongue slightly coated; he has taken plenty of milk and beef-tea, without sickness. Ordered a mixture containing tincture of opium, compound spirit of ammonia, spirit of chloroform, and tincture of catechu, every three hours, and two teaspoonfuls of brandy every two hours, with warmth to the surface by hot flannels and a hot-water bottle. He, however, did not rally, and died at 2.45 next morning. The post-mortem examination showed that death was due to intestinal obstruction, the seat of obstruction being the sigmoid flexure of the colon, which was tightly packed with hard scybala.

CASE 3. Acute intestinal obstruction simulating choleraic diarrhcea.-Arthur T - an idiot boy aged fifteen. Aug. 17th, 1886: The last fortnight he has been suffering from disordered bowels, apparently diarrhœea, the motions being liquid and of a dark-green colour (according to the nurse). During this time he has been sick twice, and has not taken his food as well as usual. This morning the symptoms suddenly became more acute, he vomited repeatedly during the day, and there was an almost constant liquid flux from the bowels. Towards evening he became very much exhausted, the pulse being quick and feeble and the hands and feet cold. Stimulants, astringents, and sedatives were administered freely without effect.-18th: This morning, at 8 o'clock, he looks very bad; he is hollow eyed, the surface is cold and clammy, and there is no pulse perceptible. $\mathrm{He}_{\theta}$ has been sick only once during the night, but there is almost constant retching, and the diarrhoea has continued almost incessantly, the stools being liquid and of a peculiar muddy colour. The character of the stocls called to mind the previous case; the rectum was therefore examined with tine finger, and just at its tip a hardened mass of fæces was felt in the upper part of the rectum. An attempt was made to break it down, and then a copious enema was administered. Nothing came away immediately, but about two hours afterwards a piece of slate pencil $2 \frac{1}{8}$ in. long was extracted from the rectum with the finger; subsequently, after repeated enemata, a quantity of small pieces of slate pencil about an inch long, a few bits of stick, some pieces of rag, and fragments of wool, came away. All the bad symptoms passed off, and the boy rapidly recovered.

\section{BULLET WOUND OF SPINE; PARALYSIS; SECONDARY ABSCESSES; DEATH.}

By JUSTYN GEO. D. DOUGLAS, M.D., C.M., HONORARY SURGEON, BOURNEMOUTH COTTAGE HOSPITAL, ETC.

BULLET wounds occurring in civil practice are comparatively rare, and the records of any case are always of sufficient interest to merit their publication. The following notes of a recent tragical case that has happened in a quiet seaside town, presenting some unique features, will probably be deserving of perusal.

Walter W-, aged forty-four years, a gentleman of independent means, following no profession, when on a visit to Bournemouth, went out for a walk on the Common near Westbourne, between 4 and 5 o'clock on the afternoon of Sept. 11th, 1886. He overtook and passed a man walking in the same direction, who was going more slowly and who appeared to be lame. After getting some five or six yards beyond him, he was suddenly shot in the back and fell to the ground, the man firing two other shots at him from a revolver. Assistance being rapidly procured, the assailant was secured and Mr. W - carefully conveyed to the Bournemouth Cottage Hospital, where he was temporarily attended by Dr. Snow (in the absence of myself and the other surgeons), who found him conscious, but in a state of collapse, complaining of pain in the back, numbness, and inability to move his legs freely. At 8 P.M., an examination of the wound showed a small circular opening about the level of the tenth dorsal vertebra, a little to the left of the mesial line of the spine. A probe was carefully passed down for about an inch and a half, but no bullet could be felt; there was some oedema round the wound and oozing of blood. There was found to be slight movement in the legs, but sensation was impaired, especially in the calves of the legs and dorsum of the feet. The right ear had been penetrated by a bullet, there being a small circular opening through the concha. As the patient was still suffering from shock, further examination was not deemed advisable. A pledget of lint dipped in carbolic onl was applied to the wound and some ice put over the part. Two ten-minim doses of tincture of opium had been administered at 6 and 7 P.M., and as there was still a good deal of pain over the lower part of the back and abdomen, twenty minims of tincture of opium were ordered at 9.30 P.M. The patient could not pass his urine. There was no vomiting, and he took a few ounces of Liebig's beef-tea.

Sept. 12th.-The patient passed a bad night, suffering from a good deal of pain and restlessness; one-sixth of a grain of morphia, given hypodermically about noon, afforded great relief. Owing to the serious nature of the case, his depositions were taken bufore a magistrate, who attended in the afternoon. About an ounce of clear urine was voided. Temperature in the morning $996^{\circ}$; evening $1006^{\circ}$. Pulse in the morning 88 ; evening 108.

13th.-Quiet night after two hypodermic injections of morphia. Twenty-nine ounces of urine drawn off in the morning, very bloody, probably from kidneys. Bowels confined; two enemata, which were used to empty them, were not retained owing to the relaxed condition of the sphincter. Temperature, $1002^{\circ}$; pulse, 108. Mr. Victor Horsley came down this evening and examined the patient. After consultation, it was considered that there was no local evidence of injury to the spinal cord itself; the partial loss of movements in the legs and the impaired sensation 